\title{
TEMPERATURE-DEPENDENT GONADAL HYBRID DYSGENESIS IN Drosophila willistoni
}

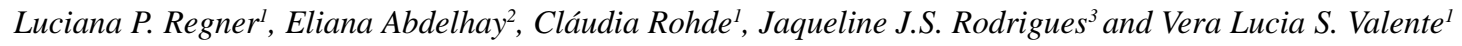

\begin{abstract}
Temperature-dependent gonadal dysgenesis was shown to occur in the progeny of both inter- and intrastrain crosses involving two populations of Drosophila willistoni, one of which was an old laboratory stock, and the other, freshly collected from a natural population. We propose that the phenomenon observed was caused by the mobilization of transposable elements, as occurs in several other Drosophila species.
\end{abstract}

\section{INTRODUCTION}

In Drosophila melanogaster, $P$ element transposition leads to a syndrome of aberrant genetic traits known as P-M hybrid dysgenesis (Kidwell et al., 1977; Bingham et al., 1982; Sved, 1987). Early investigations identified two alternative states, or cytotypes, which are determined by a combination of chromosomal and cytoplasmic factors that allow or repress transposition (Engels and Preston, 1979; Engels, 1983). The M cytotype is permissive and is characteristic of D. melanogaster strains that are completely devoid of $P$ elements, i.e., $\mathrm{M}$ strains. The $\mathrm{P}$ cytotype is non-permissive, and is characteristic of $\mathrm{P}$ strains, i.e., those carrying many copies of autonomous $P$ elements. More recent studies have revealed considerable variation in the inheritance of these regulatory states (Kidwell, 1985; Simmons et al., 1987, 1990). Since these states are tissue-specific, they are confined to the germline of the progeny produced by certain interstrain crosses. Dysgenic traits include temperature-sensitive sterility and reduced viability and fecundity, which in turn lead to a reduction in organism fitness.

In addition to the P-M system, other families of transposal elements are capable of promoting hybrid dysgenesis. Of these, I-R (Bucheton et al., 1976, 1984, 1986) and H-E (Blackman et al., 1987; Yannopoulos et al., 1987) have been particularly well studied. Lozovskaya et al. (1990) also demonstrated the occurrence of hybrid dysgenesis syndrome in $D$. virilis when the male parent came from a long-established laboratory strain. This hybrid dysgenesis system was attributed to the Ulysses transposable

\footnotetext{
${ }^{1}$ Departamento de Genética, Instituto de Biociências, Universidade Federal do Rio Grande do Sul, Caixa Postal 15053, 91501-970 Porto Alegre, RS, Brasil. Send correspondence to V.L.S.V. E-mail: valente@if1.if.ufrgs.br

${ }^{2}$ Laboratório de Biologia Molecular Maury Miranda, Instituto de Biofísica Carlos Chagas Filho, Universidade Federal do Rio de Janeiro, Centro de Ciências da Saúde, Bloco G, Ilha Universitária, 21949-900 Rio de Janeiro, RJ, Brasil.

${ }^{3}$ Departamento de Biotecnologia, Instituto de Biociências, Universidade Federal do Rio Grande do Sul, 91501-900 Porto Alegre, RS, Brasil.
}

element and, more recently, to at least four transposable elements (Petrov et al., 1995). A similar situation, characterized by gonadal dysgenesis and the presence of chromosomal aberrations, was also recently reported by Torti et al. (1994) for the medfly Ceratitis capitata.

Drosophila willistoni is a Neotropical species considered a paradigm for evolutionary studies (Dobzhansky and Powell, 1975; Ehrman and Powell, 1982; Cordeiro and Winge, 1995). Over the last decade, we have studied this species using genetic, ecological and evolutionary approaches (Valente and Araújo, 1985, 1986a,b, 1991; Valente et al., 1993).

In an effort to identify the causal agents of the reduced viability of hybrid strains produced by crossing laboratory and natural populations of $D$. willistoni, and to analyze chromosomal inversions, we examined a series of traits that resembled previously studied gonadal dysgenesis syndromes (Kidwell et al., 1977; Blackman et al., 1987; Lozovskaya et al., 1990). In this paper, we report the occurrence and some characteristics of a dysgenesis-like phenomenon in D. willistoni.

\section{MATERIAL AND METHODS}

\section{Fly stocks and culture conditions}

Two stocks of D. willistoni (WIP-11A and 17A2) were used. $17 \mathrm{~A} 2$ was a wild-derived $D$. willistoni stock that had been in the laboratory since 1991 and was established from a natural population collected in a wilderness area (Eldorado do Sul, southern Brazil, 3005' S-51 ${ }^{\circ} 39^{\prime} \mathrm{W}$ ). WIP-11A was a subculture of an old laboratory stock (WIP4 ), originally collected in the "caatinga" desert near the city of Salvador (12 ${ }^{\circ} 54^{\prime}$ 'S $-38^{\circ} 19^{\prime} \mathrm{W}$ ), in northeastern Brazil and had been kept in the laboratory for 30 years. All cultures were maintained by mass matings on standard Drosophila culture media (Marques et al., 1966).

\section{Gonadal sterility tests}

Gonadal sterility was scored in the F1 progeny of inter- and intrastrain crosses involving WIP-11A and 17A2 flies. Each cross was performed by mass mating 30 virgin 
females with 30 virgin males at $18^{\circ}, 25^{\circ}$ and $29+1^{\circ} \mathrm{C}$. At the onset of eclosion, $\mathrm{F} 1$ progeny was transferred to fresh culture vials and aged for five days at $25 \pm 1^{\circ} \mathrm{C}$. F1 males and females were then dissected in a drop of Ephrussi and Beadle (1936) saline solution. The frequency of gonadal sterility was calculated by dividing the number of dysgenic gonads by the total number of gonads.

Chi-square test was performed to assess the statistical significance of the differences among the crosses, sexes and temperatures, relative to the number of dysgenic gonads observed in the F1.

\section{RESULTS}

An elevation in environment temperature during mating increased the levels of gonadal dysgenesis in $D$. willistoni hybrid progenies. Dissection of the reproductive tract of both male and female F1 progeny from the four possible crosses involving WIP-11A and 17A2 revealed gonadal underdevelopment in several cases (Figure 1 and Table I). Although not shown, unilaterally dysgenic gonads were also observed.
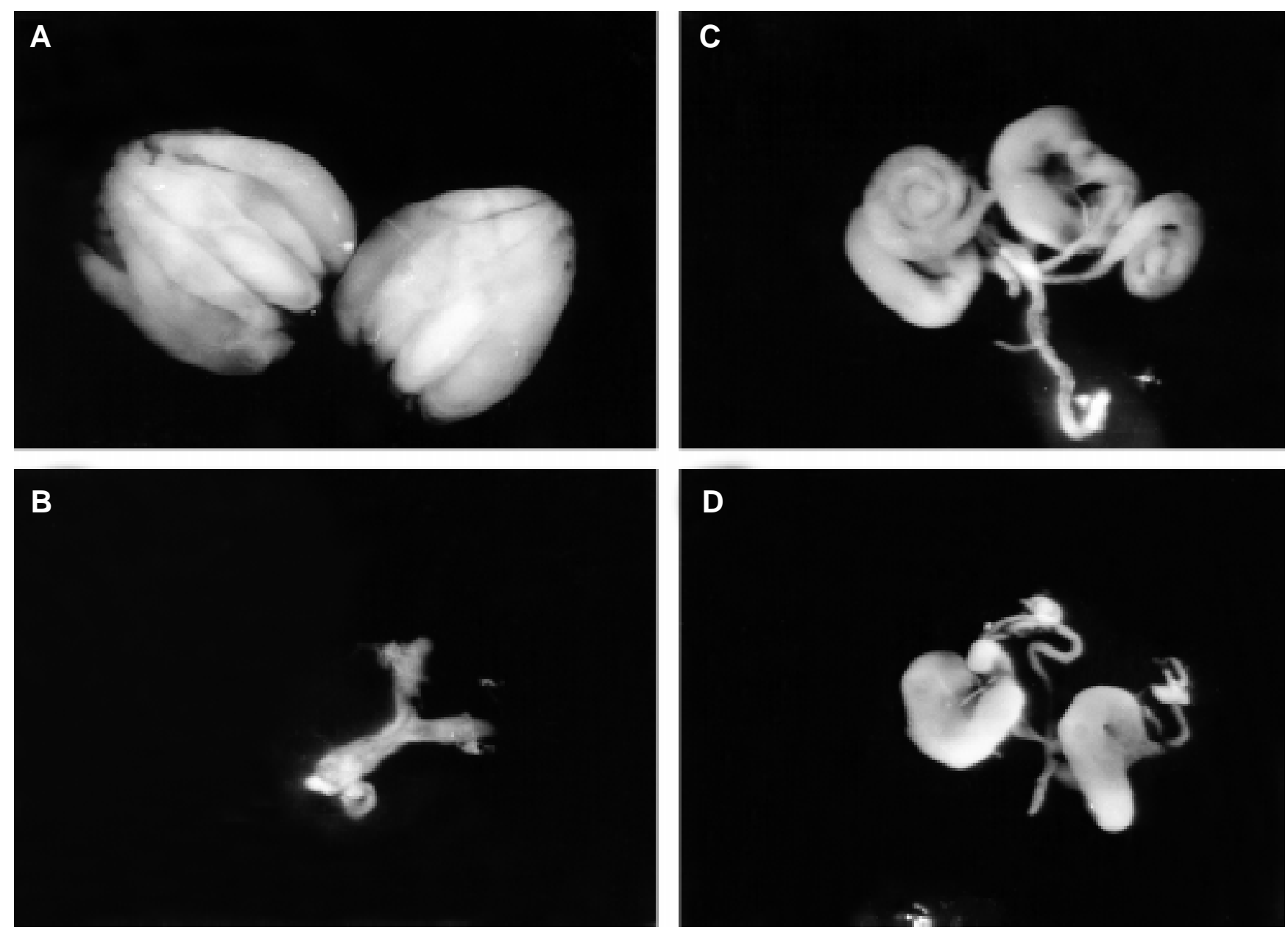

Figure 1 - Extreme phenotypes suggestive of gonadal dysgenesis in D. willistoni. A) Normal ovaries; (B) Bilaterally dysgenic ovaries; (C) Normal testes; (D) Bilaterally dysgenic testes.

In addition to complete ovarian reduction in the $\mathrm{F} 1$ progeny, some intermediate forms consisting of partially reduced ovaries containing only one or a few ovarioles were also detected. However, these intermediate phenotypes were excluded from the calculations of ovarian dysgenesis so as to avoid superestimation of the phenomenon as a result of the possible loss of parts of these soft, small structures during handling. Significant gonadal dysgenesis occurred at $29^{\circ} \mathrm{C}$ in all the crosses performed, with exception of the WIP-11A intrastrain cross. In this case, the levels of gonadal dysgenesis were trivial, occurring at nearly equal frequencies at all three temperatures at which the flies were mated and the F1 progeny developed. The statistical significance of the differences in gonadal dysgenesis levels is summarized in Table II.

The percentages of F1 dysgenic gonads were considerably higher in the second and third crosses (Table I) at $29^{\circ} \mathrm{C}$. At $18^{\circ}$ and $25^{\circ} \mathrm{C}$, the levels of sterility in these crosses were very similar to those observed in the WIP$11 \mathrm{~A}$ intrastrain cross. Considering all crosses, males and females were not equally affected. At $29^{\circ} \mathrm{C}$, male descendants of the three last crosses showed similar proportions 
Table I - Gonadal dysgenesis (GD) sterility in female and male F1 progeny of $D$. willistoni at different temperatures.

\begin{tabular}{|lcrrrr|}
\hline Cross type & Temperature & \multicolumn{2}{c}{ F1 Females } & \multicolumn{2}{c|}{ F1 Males } \\
\cline { 2 - 6 } & ${ }^{0} \mathrm{C}$ & \% GD & $\mathrm{N}$ & \% GD & $\mathrm{N}$ \\
\hline WIP-11A females x & 18 & 2.2 & 184 & 1.7 & 174 \\
WIP-11A males & 25 & 1.1 & 174 & 1.2 & 160 \\
& 29 & 3.4 & 178 & 2.4 & 126 \\
WIP-11A females x & 18 & 0.9 & 216 & 2.8 & 216 \\
17A2 males & 25 & 0.0 & 180 & 2.4 & 168 \\
& 29 & 26.1 & 180 & 20.6 & 102 \\
17A2 females x & 18 & 0.0 & 190 & 2.0 & 196 \\
WIP-11Amales & 25 & 1.2 & 168 & 0.0 & 156 \\
& 29 & 18.8 & 170 & 14.0 & 100 \\
17A2 females x & 18 & 2.2 & 180 & 2.5 & 162 \\
17A2 males & 25 & 5.5 & 182 & 1.7 & 172 \\
& 29 & 16.3 & 172 & 13.1 & 122 \\
\hline
\end{tabular}

$\mathrm{N}=$ Number of ovaries (females) or testes (males) analyzed.

Table II - Contingency table for testing the effects of female and male gonadal dysgenesis (GD) at $29^{\circ} \mathrm{C}$

\begin{tabular}{|lccccc|}
\hline \multirow{2}{*}{ Cross type } & \multicolumn{2}{c}{ F1 Females } & \multicolumn{2}{c|}{ F1 Males } \\
\cline { 2 - 5 } & GD & NG & GD & NG \\
\hline $\begin{array}{l}\text { WIP-11A females } x \\
\begin{array}{l}\text { WIP-11A males } \\
\text { WIP-11A females } x\end{array}\end{array}$ & $6^{*}$ & 172 & $3^{*}$ & 123 \\
$\begin{array}{l}\text { 17A2 males } \\
\text { 17A2 females } x\end{array}$ & 32 & 138 & 14 & 86 \\
$\begin{array}{l}\text { WIP-11A males } \\
\text { 17A2 females x }\end{array}$ & 28 & 144 & 16 & 106 \\
17A2 males & & & & & \\
\hline
\end{tabular}

$\chi^{2}=35.567, \mathrm{P}=0.001$ (significant heterogeneity among females of the four crosses). $\chi^{2}=18.687, \mathrm{P}=0.001$ (significant heterogeneity among males of the four crosses). * Residual analysis indicating a lack of GD. ** Residual analysis indicating an excess of GD. $\chi^{2}=5.651, \mathrm{P}=0.059$ (nonsignificant variation in female GD among the last three crosses). $\chi^{2}=2.670, \mathrm{P}=0.263$ (nonsignificant variation in male GD among the last three crosses). GD = number of dysgenic gonads, $\mathrm{GN}=$ number of normal gonads.

of gonadal dysgenesis, whereas the females tended to have slightly higher sterility rates compared with males in the second and fourth crosses.

These results (Table I) suggest that gonadal sterility in D. willistoni is a temperature-dependent phenomenon, but different from the $P$-induced response in $D$. melanogaster. However, temperature alone did not induce the gonadal alterations observed since WIP-11A flies had similar levels of dysgenesis at all developmental temperatures and F1 female descendants of the cross of 17A2 males and females reared at $25^{\circ} \mathrm{C}$ also had an elevated frequency of dysgenic gonads. Thus, $D$. willistoni hybrid sterility is not independent of the cross direction (Table I).

In addition to gonadal dysgenesis, certain altered phenotypes were also observed in the offspring of WIP$11 \mathrm{~A}$ and $17 \mathrm{~A} 2$ crosses kept at $29^{\circ} \mathrm{C}$. These were similar to those of certain $P$-induced $D$. melanogaster mutants described by Lindsley and Zimm (1990). In our case, the low viability of the individuals affected meant that it was impossible to maintain them long enough to carry out crosses to differentiate these phenotypes from microorganism-promoted aberrant phenotypes and/or heat-induced phenocopies. However, we think that such phenotypes deserve attention because of their similarity to $P$-induced mutants. Specifically, they were similar to i) Beadex, based on their diminished 5th wing vein and/or the presence of "bubbles" or excisions at their edges (Figure 2B,C,E), ii) held-up, based on the vertical position of the wing insertion (Figure 2I), iii) Notch, based on shrinkage of the 5th wing vein or on the enlarged veins, with deltae in the extremities, and/or in the serrated edges. Sparse thoracic hairs with irregular distribution (Figure 3B), the presence of an intermediate thoracic furrow (Figure 3D) and some changes in the color, size, shape and arrangement of the eye ommatidia were also observed (Figure 4B,C and D), and iv) extra-eye, based on the duplication of head structures, that in extreme cases seemed to form supernumerary eyes (Figure 3D).

\section{DISCUSSION}

This study is the first report of gonadal dysgenesis in D. willistoni, although no causal relationship between the observed gonadal dysgenesis and transposon-homologous sequence was established. The alterations observed in the reproductive tract of $D$. willistoni and the external phenotypes were morphologically similar to those of $P$ induced traits in D. melanogaster.

The $P$-related gonadal dysgenesis in $D$. melanogaster and the phenomenon observed in D. willistoni were also similar in that both were triggered by high temperatures, although this temperature was higher in D. willistoni $\left(>25^{\circ} \mathrm{C}\right)$ than in $D$. melanogaster $\left(23^{\circ} \mathrm{C}\right)$ (Kidwell, 1983). While this phenomenon may have been caused by transposable elements, it may also be related to the hotter habitat (hot, humid Neotropical forests) of D. willistoni, in which case the higher triggering temperature may be a species adaptation to avoid high gonadal sterility rates. Females and males were both affected, although females tended to have slightly higher sterility rates at $29^{\circ} \mathrm{C}$.

Contrary to $P$-hybrid dysgenesis in $D$. melanogaster, the percentage of gonadal dysgenesis varied in the progeny of WIP-11A females $x$ 17A2 males, 17A2 females $x$ $17 \mathrm{~A} 2$ males and 17A2 females $x$ WIP-11A males. In the first two crosses, the male parents were from the same population (17A2) and would therefore be expected to contribute approximately to the same conditions for establishing gonadal dysgenesis.

Both $D$. willistoni strains studied have DNA sequences homologous to complete $P$-elements in $D$. melanogaster, as 

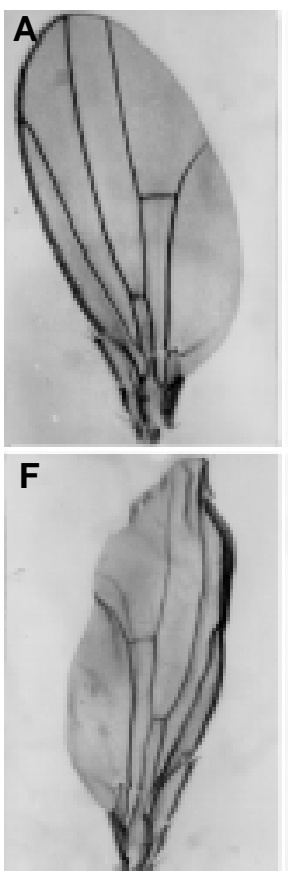

B

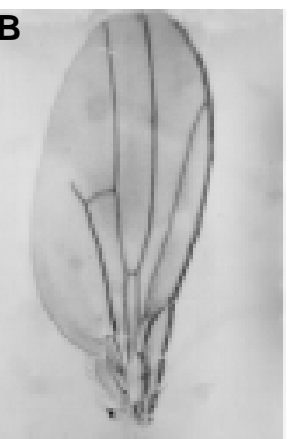

G

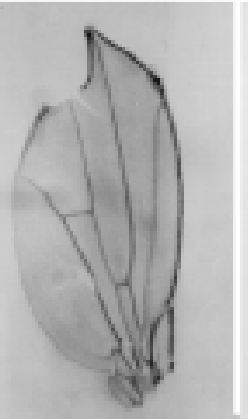

C

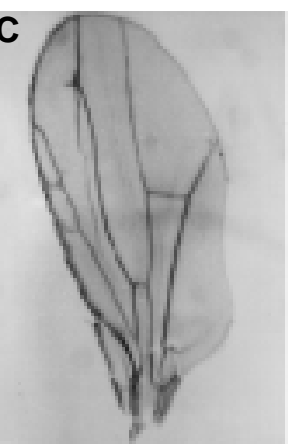

H

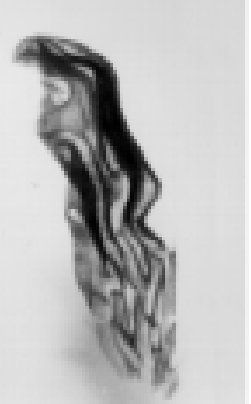

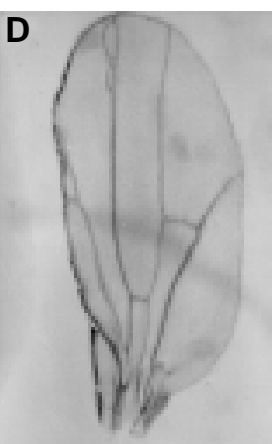

I

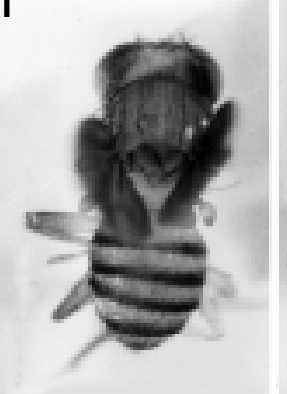

E

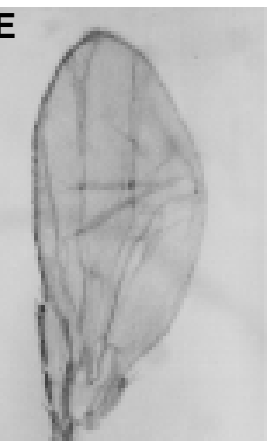

J

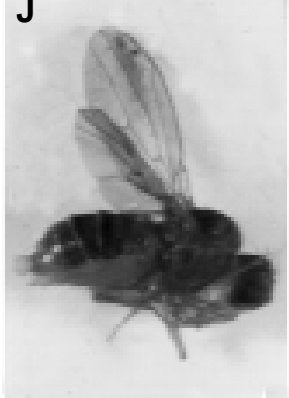

Figure 2 - Altered wing phenotypes encountered in the progeny of a WIP-11A x 17A2 cross of D. willistoni at $29^{\circ} \mathrm{C}$. (A) Wild wing; (B-E) irregular or incomplete vein formation; (E-G) incompletely expanded wings; (C, H) border of wings with reentrances; (I) abnormal wing position; (J) fly with different size wings.
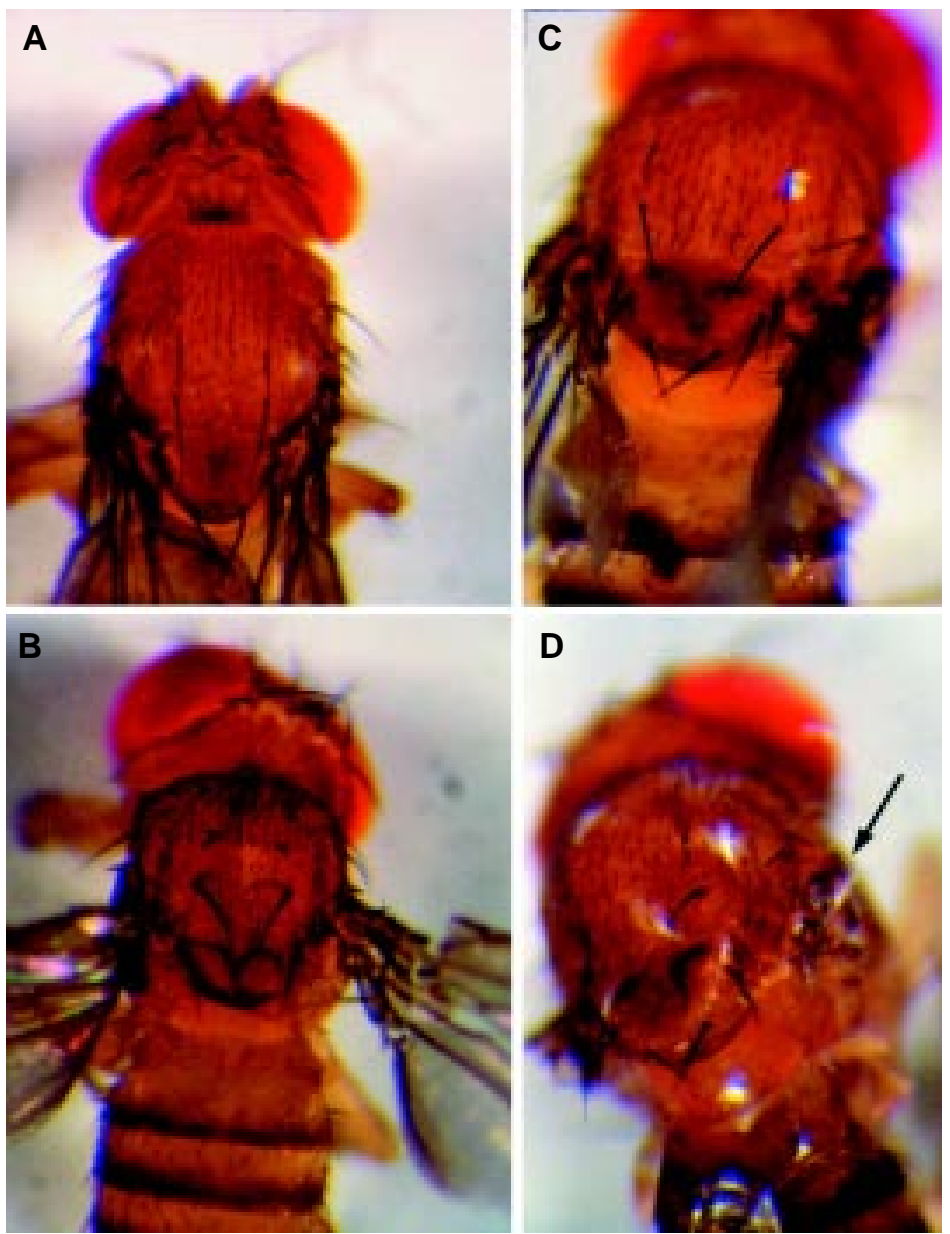

Figure 3 - Altered thorax and bristle phenotypes in the progeny of a WIP-11A x $17 \mathrm{~A} 2$ cross of D. willistoni at $29^{\circ} \mathrm{C}$. (A) Wild phenotype; (B) abnormal bristles; (C) duplication of bristles (arrow); (D) altered bristles and thorax with a furrow (arrow). 

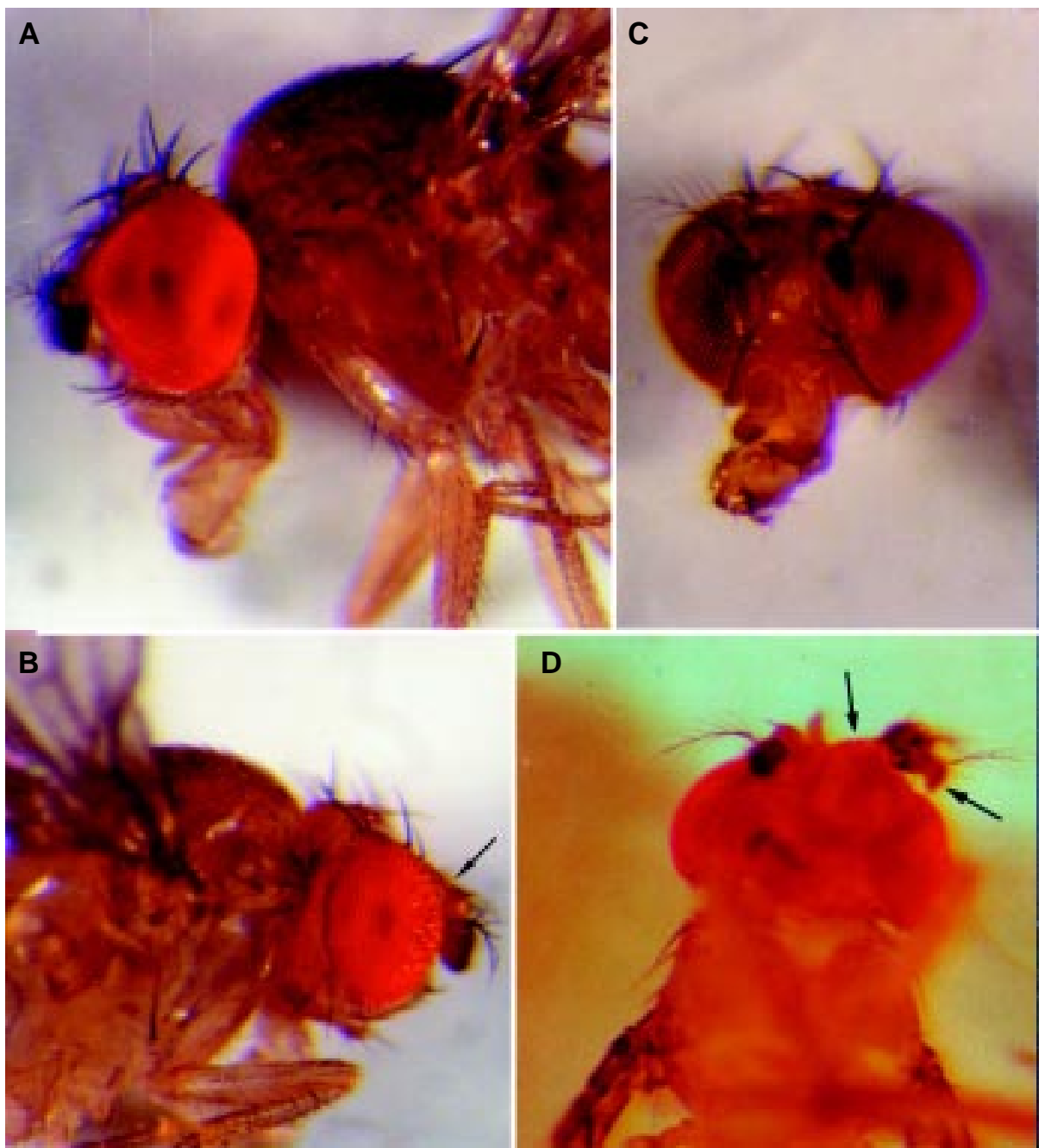

Figure 4 - Altered head and eye phenotypes in the progeny of a WIP-11A x 17A2 cross of $D$. willistoni at $29^{\circ} \mathrm{C}$. (A) Wild phenotype; (B) abnormal ommatidia (arrow); (C) different colored eyes; (D) unilateral duplication of head structures, including an extra eye and antenna (arrows).

revealed by Southern blots (Regner et al., 1996), although their genomic positions differ sharply. In situ hybridization has shown that while 17A2 has several hybridization signals in the euchromatic arms, the signals in WIP-11A are concentrated mainly in the chromocenter.

Further studies on the regulation of $P$ transposition need to be performed in species other than D. melanogaster before concluding whether this element is involved in the phenomenon described here.

In $D$. nebulosa, a close relative of $D$. willistoni, the $P$ insertion site appears to be a complex sequence that is repeated three times in this species' centromeric heterochromatin (Lansman et al., 1987). This finding led these authors to suggest that some species have $P$ element insertional "hotspots" in their heterochromatic DNA such that capture in the heterochromatin of the chromocenter could prevent the mobilization of several transposons. Transposable element invasions and re-invasions would then result in periods of dysgenic effects related to the amount of complete elements present in the genome, followed by the ac- cumulation of mobile sequences in heterochromatic hotspots and a reduction in dysgenic traits. Genomic location is possibly a strategy developed to control the effects of putative transposable element activity.

Clark et al. (1995) recently reported four major $P$ element subfamilies in the $D$. willistoni and $D$. saltans species groups, indicating that the coexistence of more than one member of these subfamilies in the same genome is possible. The implications of such differences on the crossability of different populations remain unknown.

One additional feature that deserves mention is the continuum of phenotypes observed between the two extremes (normal and dysgenic) at $29^{\circ} \mathrm{C}$. These intermediate phenotypes were very rare in D. melanogaster (their occurrence was limited to crosses performed at temperatures below $25^{\circ} \mathrm{C}$ ) but frequent in $D$. simulans (Daniels et al., 1989), and have also been reported for D. mauritiana (Montchamp-Moreau et al., 1991). However, D. simulans and $D$. mauritiana do not bear $P$ elements under natural conditions; $P$ elements were introduced into each either 
by genetic transformation experiments or by interspecific crosses. Daniels et al. (1989) suggested that the expression of sterility in $D$. simulans tended to be more depressed at lower temperatures than D. melanogaster in similar conditions. Considering the results for $D$. willistoni, we suggest that a similar phenomenon promoted by the putative transposable element involved may occur in the latter species.

Previous studies on the origin of $P$ elements suggested that these sequences are a new acquisition of $D$. melanogaster, but were harbored for a longer time in $D$. willistoni (Kidwell, 1983; Daniels and Strausbaugh, 1986; Daniels et al., 1990a; Houck et al., 1991). The latter species may have had to deal with $P$ activity for a longer period than $D$. melanogaster which may not have had enough time to adapt to the effects of this elemental system. Indeed, Daniels et al. (1990a) suggested that hybrid dysgenesis may be different in these two species. Although our results do not constitute a thorough investigation of hybrid dysgenesis in $D$. willistoni, the results of gonadal sterility tests showed common basic features, suggesting that the differences between these two species may be more of a quantitative than a qualitative nature. Several types of evidence have led some to the conclusion that $P$ element expression is influenced by certain host properties (Rio et al., 1986; O'Brochta and Handler, 1988; Rio and Rubin, 1988; Rio, 1990). These properties, however, do not seem to differ much between $D$. willistoni and D. melanogaster, since a complete $P$ element from $D$. willistoni can promote transposition in D. melanogaster (Daniels et al., 1990a), and a complete $P$ element of $D$. melanogaster can be excised from $D$. willistoni (O'Brochta and Handler, 1988).

Other transposable element families, such as hobo, are also able to promote gonadal dysgenesis similar to the $P$ element in Drosophila (Blackman et al., 1987). However, D. willistoni has been reported to be devoid of hobo (Daniels et al., 1990b), thus weakening the possible involvement of hobo in the phenomenon we observed. However, we have recently reported weak hobo hybridization signals in the genome of some $D$. willistoni strains (including those here studied) (Loreto et al., 1998), that deserve future study.

It is possible that an unknown element harbored exclusively by some natural populations of $D$. willistoni, and/or that several unrelated transposable elements, as found in D. virilis (Petrov et al., 1995), could be responsible for the generation of phenomena such as those described here.

Other conditions, such as the presence of endocytobionts like the rickettsia Wolbachia, can promote intraspecific reproductive incompatibility. When this microorganism is present in one population and not in another, either no hybrids or fewer progeny are produced. This phenomenon affects females from one reciprocal cross, but not those from the other (for a review, see Hoy,
1994). This possibility is unlikely to explain the data reported here.

Considering this scenario, and the possible evolutionary consequences of the intraspecific incompatibility described here as well as the fact that environmental stress is capable of promoting transposon mobilization (JouanDofournel et al., 1996), we believe that exploration of the role of transposable elements as a source of genetic variability in natural populations of Neotropical Drosophila species has only just begun.

\section{ACKNOWLEDGMENTS}

This research was supported by grants and fellowships from Conselho Nacional de Desenvolvimento Científico e Tecnológico (CNPq), Fundação de Amparo à Pesquisa do Estado do Rio Grande do Sul (FAPERGS), Financiadora de Estudos e Projetos (FINEP), Pró-Reitoria de Pesquisa e Pós-Graduação da Universidade Federal do Rio Grande do Sul and Fundação de Amparo à Pesquisa do Estado do Rio de Janeiro (FAPERJ).

\section{RESUMO}

Disgenesia gonadal dependente de temperatura foi encontrada na prole tanto de cruzamentos intra como interlinhagens, envolvendo duas populações de Drosophila willistoni. Uma delas é derivada de um velho estoque de laboratório e a outra, de uma amostra recentemente coletada de uma população natural. Tal fenômeno não havia ainda sido descrito em $D$. willistoni e nós sugerimos que a disgenesia gonadal encontrada seja causada por elementos transponíveis, como ocorre em muitas outras espécies de Drosophila.

\section{REFERENCES}

Bingham, P.M., Kidwell, M.G. and Rubin, G.M. (1982). The molecular basis of P-M hybrid dysgenesis: the role of the $P$ element, a $P$-strainspecific transposon family. Cell 29: 995-1004.

Blackman, R., Grimaila, R., Koehler, M. and Gelbart, W. (1987). Mobilization of hobo elements residing within the decapentaplegic gene complex: suggestion of a new hybrid dysgenesis system in Drosophila melanogaster. Cell 49: 497-505.

Bucheton, A., Lavige, J.M., Picard, G. and Heritier P. (1976). Non- Mendelian female sterility in Drosophila melanogaster: quantitative variation in the efficiency of inducer and reactive strains. Heredity 36 : 305-314.

Bucheton, A., Paro, R., Sang, H.M., Pelisson, A. and Finnegan, D.J. (1984). The molecular basis of I-R hybrid dysgenesis: identification, cloning and properties of the I factor. Cell 38: 153-163.

Bucheton, A., Simonelig, M., Vaury, C. and Crozatier, M. (1986). Sequences similar to the $I$ transposable element involved in I-R hybrid dysgenesis occur in other Drosophila species. Nature 322: 650-652.

Clark, J.B., Altheide, T.K., Schlosser, M.J. and Kidwell, M.G. (1995). Molecular evolution of $P$ transposable elements in the genus Drosophila. I. The saltans and the willistoni groups. Mol. Biol. Evol. 12: 902-913

Cordeiro, A.R. and Winge, H. (1995). Levels of evolutionary divergence of Drosophila willistoni sibling species. In: Genetics of Natural Populations. The Continuing Importance of Theodosius Dobzhansky (Levine, L., ed.). Columbia University Press, New York, pp. 262280.

Daniels, S.B. and Strausbaugh, L.D. (1986). The distribution of $P$ element sequences in Drosophila: the willistoni and saltans species groups. 
J. Mol. Evol. 23: 138-148.

Daniels, S.B., Chovnick, A. and Kidwell, M. (1989). Hybrid dysgenesis in Drosophila simulans lines transformed with $P$ elements. Genetics 121: 281-291.

Daniels, S.B., Chovnick, A. and Boussy, I.A. (1990a). Distribution of hobo transposable elements in the genus Drosophila. Mol. Biol. Evol. 7: 589-606.

Daniels, S.B., Peterson, K.R., Strausbaugh, L.D., Kidwell, M.G. and Chovnick, A. (1990b). Evidence of horizontal transmission of the $P$ transposable element between Drosophila species. Genetics 124: 339 355.

Dobzhansky, T. and Powell, J.R. (1975). The willistoni group of sibling species of Drosophila. In: Handbook of Genetics (King, R.C., ed.). Vol. 3. Plenum Publ. Corp., New York, pp. 589-622.

Ehrman, L. and Powell, J.R. (1982). The Drosophila willistoni species group. In: The Genetics and Biology of Drosophila (Ashburner, M., Carson, H.L. and Thompson Jr, J.N., eds.). Vol. 3b. Academic Press, New York, pp. 193-225.

Engels, W.R. (1983). The $P$ family of transposable elements in Drosophila. Annu. Rev. Genet. 17: 315-344.

Engels, W.R. and Preston, C.R. (1979). Hybrid dysgenesis in Drosophila melanogaster: nature and inheritance of $P$ element regulation. $G e$ netics 92: 161-175.

Ephrussi, B. and Beadle, G.W. (1936). A technique of transplantation for Drosophila melanogaster. Am. Nat. 70: 218-225.

Houck, M.A., Clark, J.B., Peterson, K.R. and Kidwell, M.G. (1991) Possible horizontal transfer of Drosophila genes by the mite Proctolaelaps regalis. Science 25: 1125-1128.

Hoy, M.A. (Ed.) (1994). Genes, genome organization, and development in insects. In: Insect Molecular Genetics. An Introduction to Principles and Applications. Academic Press, San Diego, pp. 69-125.

Jouan-Dufournel, I., Cosset, F., Contamine, D., Verdier, G. and Biémont, C. (1996). Transposable element behavior following viral stress in Drosophila melanogaster inbred line. J. Mol. Evol. 43: 19-27.

Kidwell, M.G. (1983). Evolution of hybrid dysgenesis determinants in Drosophila melanogaster. Proc. Natl. Acad. Sci USA 80: 1655-1659.

Kidwell, M.G. (1985). Hybrid dysgenesis in Drosophila melanogaster: nature and inheritance of $P$ element regulation. Genetics 111: 337-350.

Kidwell, M.G., Kidwell, J.F. and Sved, J.A. (1977). Hybrid dysgenesis in Drosophila melanogaster: a syndrome of aberrant traits including mutation, sterility, and male recombination. Genetics 36: 813-833.

Lansman, R.A., Shade, R.O., Grigliatti, T.A. and Brock, H.W. (1987). Evolution of $P$ transposable elements: sequences of Drosophila nebulosa P elements. Proc. Natl. Acad. Sci. USA 84: 6491-6495.

Lindsley, D.L. and Zimm, G.G. (1990). The Genome of Drosophila melanogaster. Academic Press, San Diego.

Loreto, E.L.S., Basso da Silva, L., Zaha, A. and Valente, V.L.S. (1998) Distribution of transposable elements in Neotropical species of Drosophila. Genetica 101: 153-165.

Lozovskaya, E.R., Scheinker, V.S. and Evgen'ev, M. (1990). A hybrid dysgenesis syndrome in Drosophila virilis. Genetics 126: 619-623.

Marques, E.K., Napp, M., Winge, H. and Cordeiro, A.R. (1966). A corn meal, soybean flour, wheat germ medium for Drosophila. Drosophila Inf. Serv. 41: 187.

Montchamp-Moreau, C., Periquet, G. and Anxolabéhère, D. (1991). Interspecific transfer of $P$ elements by crosses between Drosophila simulans and Drosophila mauritiana. J. Evol. Biol. 4: 131-140.

O'Brochta, D.A. and Handler, A.M. (1988). Mobility of $P$ elements in drosophilids and nondrosophilids. Proc. Natl. Acad. Sci. USA 85 6052-6056.

Petrov, D.A, Schutzman, J.L., Hartl, D. and Lozovskaya, E.R. (1995) Diverse transposable elements are mobilized in hybrid dysgenesis in Drosophila virilis. Proc. Natl. Acad. Sci. USA 92: 8050-8054.

Regner, L.P., Pereira, M.S.O., Alonso, C.E.V., Abdelhay, E. and Valente, V.L.S. (1996). Genomic distribution of $P$ elements in Drosophila willistoni and a search for their relationship with chromosomal inversions. J. Hered. 87: 190-211.

Rio, D.C. (1990). Molecular mechanisms regulating Drosophila P element transposition. Annu. Rev. Genet. 24: 543-578.

Rio, D.C. and Rubin, G.M. (1988). Identification and purification of a Drosophila protein that binds to the terminal 31-base-pair inverted repeats of the $P$ transposable element. Proc. Natl. Acad. Sci. USA 85: 8929-8933.

Rio, D.C., Laski, F.A. and Rubin, G.M. (1986). Identification and immunochemical analysis of biologically active Drosophila $P$ element transposase. Cell 44: 21-32.

Simmons, J.M., Raymond, J.D., Boedigheimer, M.J. and Zunt, J.R. (1987). The influence of non-autonomous $P$ elements on hybrid dysgenesis in Drosophila melanogaster. Genetics 117: 671-685.

Simmons, J.M., Raymond, J.D., Rasmusson, K.E., Miller, L.M., McLarnon, C.F. and Zunt, J.R. (1990). Repression of $P$ element-mediated hybrid dysgenesis in Drosophila melanogaster. Genetics 124 : 663-676.

Sved, J.A. (1987). Hybrid dysgenesis in Drosophila melanogaster, evidence from sterility and Southern hybridization tests that $\mathrm{P}$ cytotype is not maintained in the absence of chromosomal P factors. Genetics 115: 121-127.

Torti, C., Malacrida, A.R., Yannopoulos, G., Louis, G. and Gasperi, G. (1994). Hybrid dysgenesis-like phenomena in the medfly, Ceratiti capitata (Diptera, Tephritidae). J. Hered. 85: 92-99.

Valente, V.L.S. and Araújo, A.M. (1985). Observations on the chromosomal polymorphism of natural populations of Drosophila willistoni and its association with the choice of feeding and breeding sites Rev. Bras. Genét. 8: 271-284.

Valente, V.L.S. and Araújo, A.M. (1986a). Chromosomal polymorphism, climatic factors and variation in population size of Drosophila willistoni. Heredity 57: 149-159.

Valente, V.L.S. and Araújo, A.M. (1986b). Comments on breeding sites of Drosophila willistoni Sturtevant (Diptera, Drosophilidae). Rev. Bras. Ent. 30: 281-286.

Valente, V.L.S. and Araújo, A.M. (1991). Ecological aspects of Drosophila species inhabiting wild environments in Southern Brazil (Diptera: Drosophilidae). Rev. Bras. Ent. 35: 237-253.

Valente, V.L.S., Ruszczyk, A. and Santos, R.A. (1993). Chromosomal polymorphism in urban Drosophila willistoni. Rev. Bras. Genét. 16: $307-$ 319.

Yannopoulos, G., Stamatis, N., Monastirioti, M., Hatzopoulos, P. and Louis, C. (1987). Hobo is responsible for the induction of hybrid dysgenesis by strains of Drosophila melanogaster bearing the male recombination factor 23.5. MRF. Cell 48: 487-495.

(Received November 7, 1997) 
